\title{
Effects of T Antigen and Replication Protein A on the Initiation of DNA Synthesis by DNA Polymerase $\alpha$-Primase
}

\author{
KATHLEEN L. COLLINS AND THOMAS J. KELLY* \\ Department of Molecular Biology and Genetics, The Johns Hopkins University School of Medicine, \\ Baltimore, Maryland 21205
}

Received 29 November 1990/Accepted 16 January 1991

\begin{abstract}
Studies of simian virus 40 (SV40) DNA replication in a reconstituted cell-free system have established that $T$ antigen and two cellular replication proteins, replication protein A (RP-A) and DNA polymerase $\alpha$-primase complex, are necessary and sufficient for initiation of DNA synthesis on duplex templates containing the SV40 origin of DNA replication. To better understand the mechanism of initiation of DNA synthesis, we analyzed the functional interactions of $T$ antigen, RP-A, and DNA polymerase $\alpha$-primase on model single-stranded DNA templates. Purified DNA polymerase $\alpha$-primase was capable of initiating DNA synthesis de novo on unprimed single-stranded DNA templates. This reaction involved the synthesis of a short oligoribonucleotide primer which was then extended into a DNA chain. We observed that the synthesis of ribonucleotide primers by DNA polymerase $\alpha$-primase is dramatically stimulated by SV40 $\mathrm{T}$ antigen. The presence of $\mathrm{T}$ antigen also increased the average length of the DNA product synthesized on primed and unprimed single-stranded DNA templates. These stimulatory effects of $T$ antigen required direct contact with DNA polymerase $\alpha$-primase complex and were most marked at low template and polymerase concentrations. We also observed that the single-stranded DNA binding protein, RP-A, strongly inhibits the primase activity of DNA polymerase $\alpha$-primase, probably by blocking access of the enzyme to the template. $T$ antigen partially reversed the inhibition caused by RP-A. Our data support a model in which DNA priming is mediated by a complex between $T$ antigen and DNA polymerase $\alpha$-primase. In this model, $T$ antigen functions to facilitate the association of the DNA polymerase $\alpha$-primase with the template, while RP-A acts to suppress nonspecific priming events.
\end{abstract}

The papovavirus simian virus 40 (SV40) has proved to be a useful model system for the study of mammalian DNA replication $(5,11,13,31)$. The $S V 40$ genome is replicated by the host replication machinery in conjunction with a single viral protein, T antigen. Synthesis of the viral genome begins at a well-defined origin and, like chromosomal DNA replication, proceeds in a bidirectional and semidiscontinuous manner. The utility of this relatively simple system is exemplified by the development of a cell-free replication system $(21,22)$ which has allowed the identification of factors involved in mammalian DNA replication. As a result of work from several laboratories, seven cellular proteins have been purified which, in combination with $\mathrm{T}$ antigen, are sufficient to reconstitute bidirectional, origin-dependent DNA replication $(32,35)$.

Of the proteins essential for complete replication of the SV40 genome, only three are absolutely required for initiation of DNA synthesis on duplex templates containing the viral origin of replication: $T$ antigen, DNA polymerase $\alpha$-primase complex, and the single-stranded DNA binding protein, replication protein A (RP-A, RF-A, or HSSB) (32, $35,38)$. $T$ antigen binds to specific sequences within the origin and, in the presence of RP-A and ATP, catalyzes the local unwinding of the template $(6,7,40)$. The role of RP-A in this reaction is to stabilize the unwound single strands $(6$, $39,41)$. Following the unwinding of the duplex, the exposed single strands serve as templates for initiation of DNA synthesis by DNA polymerase $\alpha$-primase complex $(12,24$, $32,35,36,41)$. Initiation is a two-step process in which the primase activity of the complex catalyzes the synthesis of a ribonucleotide primer which is then extended into a short

\footnotetext{
* Corresponding author.
}

DNA chain by the DNA polymerase activity. In the immediate vicinity of the origin, initiation events occur with roughly equal frequency on both parental DNA strands, but in regions outside of the origin, initiation occurs preferentially on the lagging-strand template $(25,32,35)$. The synthesis of leading-strand products requires additional proteins $(25,32,33,35,36)$. It seems likely that the series of events required for initiation of SV40 DNA replication are coordinated in space and time by specific protein-protein as well as protein-DNA interactions. However, relatively little is known about the details of such interactions.

Several studies have demonstrated that two of the proteins involved in initiation, T antigen and DNA polymerase $\alpha$-primase complex, are capable of forming a specific complex. This has now been demonstrated both with crude cellular extracts $(9,10,28)$ and with purified proteins $(8)$. Recent evidence indicates that complex formation involves an interaction between $T$ antigen and the large (catalytic) subunit of DNA polymerase $\alpha(8)$. A functional role for this interaction is suggested by the observation that purified DNA polymerase $\alpha$-primase from permissive human or monkey cells is sufficient to restore $\mathrm{T}$-antigen-dependent replication activity to nonpermissive mouse cells that are otherwise inactive for SV40 replication (24). Thus, an interaction between $T$ antigen and DNA polymerase $\alpha$-primase may be an important determinant of the host-range specificity of SV40.

To better understand how $\mathrm{T}$ antigen, RP-A, and DNA polymerase $\alpha$-primase act in concert to initiate DNA synthesis, we analyzed the functional interactions of these three proteins on unprimed and primed single-stranded DNA templates. We observed that the synthesis of ribonucleotide primers by the DNA polymerase $\alpha$-primase complex on unprimed templates is dramatically stimulated by the SV40 T antigen. The presence of $\mathrm{T}$ antigen also increased the aver- 
age length of the DNA product synthesized on primed and unprimed single-stranded DNA templates. These stimulatory effects of $\mathrm{T}$ antigen required direct contact with DNA polymerase $\alpha$-primase complex and were most marked at low template and polymerase concentrations. We also observed that the single-stranded DNA binding protein, RP-A, strongly inhibits the primase activity of DNA polymerase $\alpha$-primase complex, probably by blocking interaction of the primase with the template, but that $\mathrm{T}$ antigen can partially reverse the inhibition. Our data support a model in which DNA priming is mediated by a complex formed between $T$ antigen and DNA polymerase $\alpha$-primase. In this model, $T$ antigen facilitates the association of both the primase and polymerase activities with the template, and RP-A acts to suppress nonspecific priming events.

\section{MATERIALS AND METHODS}

Protein purification. DNA polymerase $\alpha$-primase, T antigen, and RP-A were purified from HeLa cells as described previously (41). The hybridoma cell line for monoclonal antibody (MAb) 419 was obtained from American Type Culture Collection. Purified MAb 101 was the generous gift of Richard Piehl (Molecular Biology Resources). Hybridoma cell lines for MAbs 205 and 414 were obtained from Keith Peden (National Institutes of Health). All MAbs were purified with protein A-Sepharose (Pharmacia) and were dialyzed into a buffer containing $30 \mathrm{mM}$ HEPES ( $N$-2-hydroxyethylpiperazine- $N^{\prime}$-2-ethanesulfonic acid), $15 \mathrm{mM} \mathrm{KCl}, 0.25$ $\mathrm{mM}$ EDTA, and $1.0 \mathrm{mM} \mathrm{NaN}_{3}$.

Polymerase assays. Unless otherwise indicated, reaction mixtures $(25 \mu \mathrm{l})$ were assembled on ice and contained $\mathrm{T}$ antigen as indicated; $0.012 \mathrm{U}$ of polymerase $\alpha(1 \mathrm{U}$ is 1.0 nmol of deoxynucleoside triphosphate incorporated into activated calf thymus DNA in a 30 -min reaction); $0.002 \mathrm{U}$ of primase; $25 \mathrm{ng}$ of M13mp18 single-stranded DNA; $100 \mu \mathrm{M}$ each dATP, dGTP, and dTTP; $25 \mu \mathrm{M}$ dCTP; $50 \mu \mathrm{M}$ each GTP, UTP, and CTP; $4 \mathrm{mM}$ ATP; $0.25 \mu \mathrm{Ci}$ of $\left[\alpha-{ }^{32} \mathrm{P}\right] \mathrm{dCTP}$; $7.0 \mathrm{mM} \mathrm{MgCl}_{2} ; 30 \mathrm{mM}$ HEPES; $40 \mathrm{mM}$ creatine phosphate; $100 \mu \mathrm{g}$ creatine kinase per $\mathrm{ml}$; and $100 \mu \mathrm{g}$ of acetylated bovine serum albumin per $\mathrm{ml}$ (41). Preprimed reaction mixtures lacked ribonucleotide precursors and contained M13mp18 annealed to the 17-nucleotide universal primer in a 1:1 molar ratio.

Analysis of deoxynucleotide products. After incubation for $2 \mathrm{~h}$ at $37^{\circ} \mathrm{C}$, the reactions were terminated with stop buffer ( $0.5 \mathrm{mg}$ of proteinase $\mathrm{K}$ per $\mathrm{ml}, 5 \%$ sodium dodecyl sulfate, $125 \mathrm{mM}$ EDTA) for $30 \mathrm{~min}$ at $37^{\circ} \mathrm{C}$. Reaction products were separated by alkaline agarose gel electrophoresis in $30 \mathrm{mM}$ $\mathrm{NaOH}-1$ mM EDTA, and the dried gels were visualized by autoradiography. DNA synthesis was quantitated by excising the lanes from the dried gel and counting the radioactivity in liquid scintillation cocktail.

Primase assays. Reactions were performed as described above for polymerase assays, except that deoxynucleotide precursors were omitted and the concentration of CTP, added as $20 \mu \mathrm{Ci}$ of $\left[\alpha^{-32} \mathrm{P}\right] \mathrm{CTP}$, was decreased from 50 to 1 $\mu \mathrm{M}$.

Product analysis of primers. Following incubation, the reaction products were incubated with stop buffer for $30 \mathrm{~min}$ at $37^{\circ} \mathrm{C}$, phenol chloroform extracted, and precipitated overnight from ammonium acetate-ethanol in the presence of $\mathbf{3 0}$ $\mu \mathrm{g}$ of carrier tRNA. Dried samples were resuspended in loading buffer containing $35 \%$ formamide, $8 \mathrm{mM}$ EDTA, $0.09 \%$ bromphenol blue, and $0.09 \%$ xylene cyanol FF and heated for $3 \mathrm{~min}$ to $95^{\circ} \mathrm{C}$. Samples were subjected to dena-

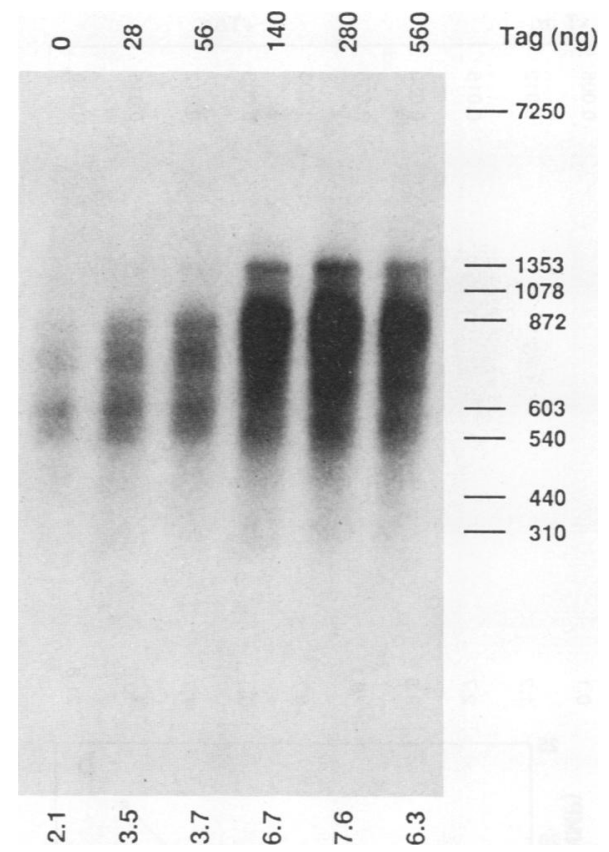

FIG. 1. Effect of T antigen (Tag) on DNA synthesis by DNA polymerase $\alpha$. Reaction mixtures $(25 \mu \mathrm{l})$ containing $0.012 \mathrm{U}$ of DNA polymerase $\alpha$ activity, $0.002 \mathrm{U}$ of primase activity, and $25 \mathrm{ng}$ of unprimed M13 single-stranded DNA were assembled on ice with the indicated amount of $\mathrm{T}$ antigen. After incubation for $2 \mathrm{~h}$ at $37^{\circ} \mathrm{C}$, samples were electrophoresed on a denaturing alkaline $2 \%$ agarose gel, dried, and visualized by autoradiography. The total DNA synthesized in each reaction mixture (picomoles) is indicated at the bottom of the figure.

turing gel electrophoresis in $20 \%$ polyacrylamide gels containing 7.0 $\mathrm{M}$ urea-Tris-borate-EDTA buffer (23) at $600 \mathrm{~V}$ for $45 \mathrm{~min}$.

\section{RESULTS}

T antigen stimulates DNA synthesis by DNA polymerase $\alpha$-primase on single-stranded DNA templates. The mammalian DNA polymerase $\alpha$ holoenzyme possesses both DNA primase and DNA polymerase activities and is capable of initiating DNA synthesis de novo on single-stranded DNA templates (for a review, see reference 20). The reaction involves the synthesis of a short oligoribonucleotide primer which is then extended into a DNA chain. To analyze the effects of $T$ antigen and RP-A on the efficiency of DNA synthesis, we studied a model system containing purified DNA polymerase $\alpha$-primase (41) and single-stranded M13 DNA as the template. Under the standard conditions used for SV40 DNA replication in vitro (41), DNA polymerase $\alpha$-primase synthesized DNA products which ranged in size from about 0.4 to $3 \mathrm{~kb}$ (Fig. 1). Addition of purified $\mathrm{T}$ antigen to this reaction stimulated DNA synthesis 4-fold (2- to 10 -fold in replicate experiments). At this level of polymerase $\alpha$-primase, the presence of $\mathrm{T}$ antigen had only a small effect on the size distribution of products; thus, the stimulation observed in this experiment was primarily due to an increase in the number of DNA chains initiated.

The degree of stimulation by $\mathrm{T}$ antigen was highly dependent on the ratio of DNA polymerase $\alpha$-primase to T antigen used in the assay. A titration of DNA polymerase $\alpha$-primase in the presence or absence of a fixed amount of $\mathrm{T}$ antigen 

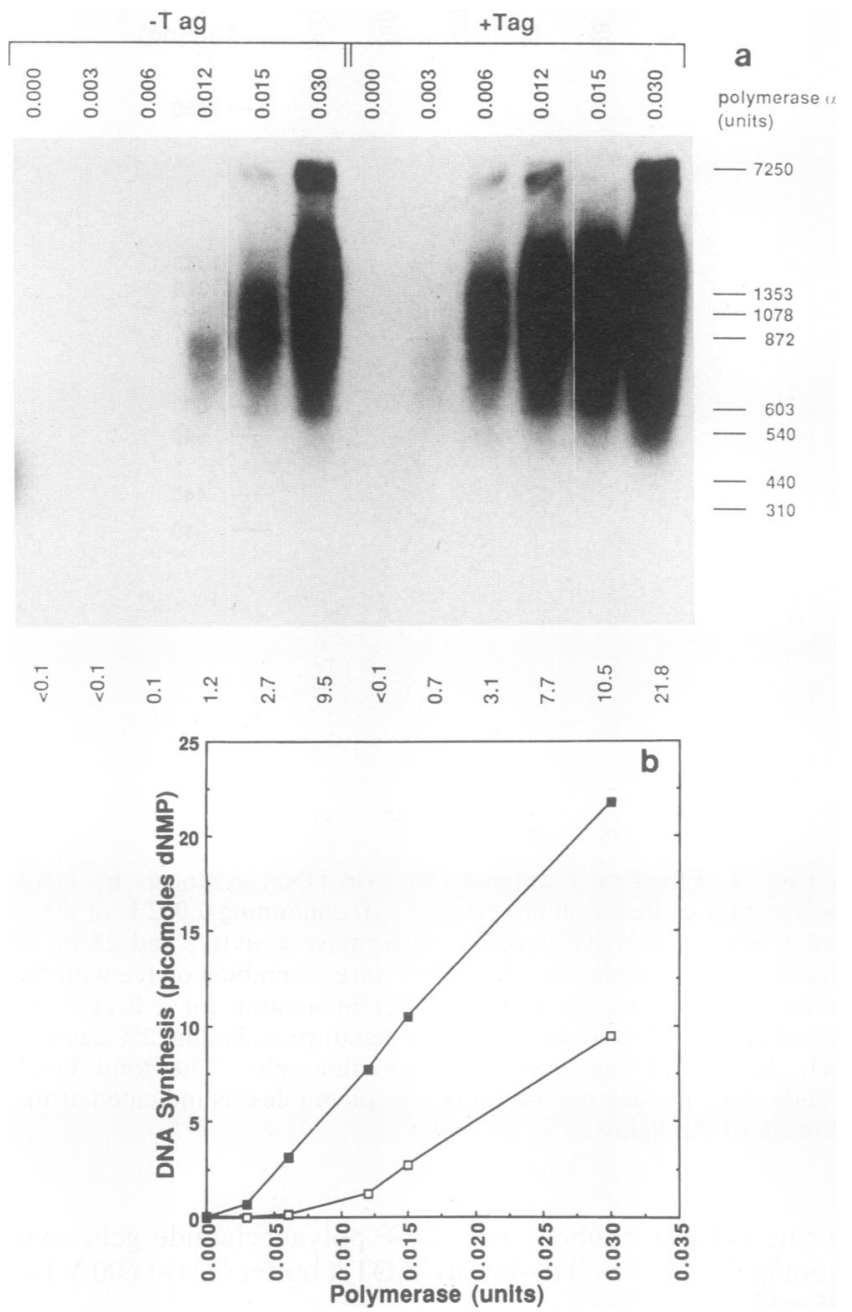

FIG. 2. Effect of DNA polymerase $\alpha$ concentration on stimulation of DNA synthesis by T antigen (Tag). (a) Electrophoretic analysis of the products. Reaction mixtures contained the indicated amount of DNA polymerase $\alpha$ and $25 \mathrm{ng}$ of unprimed M13 singlestranded DNA as the template. After incubation for $2 \mathrm{~h}$ in the presence or absence of $280 \mathrm{ng}$ of $\mathrm{T}$ antigen, the reaction products were electrophoresed on a denaturing agarose gel. Picomoles of DNA synthesized in each reaction mixture are indicated at the bottom of the figure. (b) Quantitation of DNA synthesis in the presence or absence of $T$ antigen. Samples from the gel shown in panel a containing the indicated amount of polymerase activity plus ( $\square$ ) or minus ( $\square$ ) T antigen were quantitated by excising the lanes from the dried gel and counting their radioactivity in liquid scintillation cocktail. dNMP, Deoxynucleoside monophosphate.

(Fig. 2a) revealed that at low levels of DNA polymerase $\alpha$-primase, $T$ antigen stimulated DNA synthesis at least 10 -fold. In contrast, at the highest level of polymerase $\alpha$-primase tested, the stimulation was only about twofold. Interestingly, in the absence of $\mathrm{T}$ antigen, the curve relating the amount of product synthesized to the amount of DNA polymerase present was highly sigmoidal. The addition of $\mathrm{T}$ antigen increased the linearity of this relationship (Fig. 2b).

Analysis of the time course of the reaction (Fig. 3) revealed that the rate of DNA synthesis was roughly constant over the first hour and leveled off during the second hour, in either the presence or absence of $T$ antigen. The ratio of the product synthesized in the presence of $T$ antigen

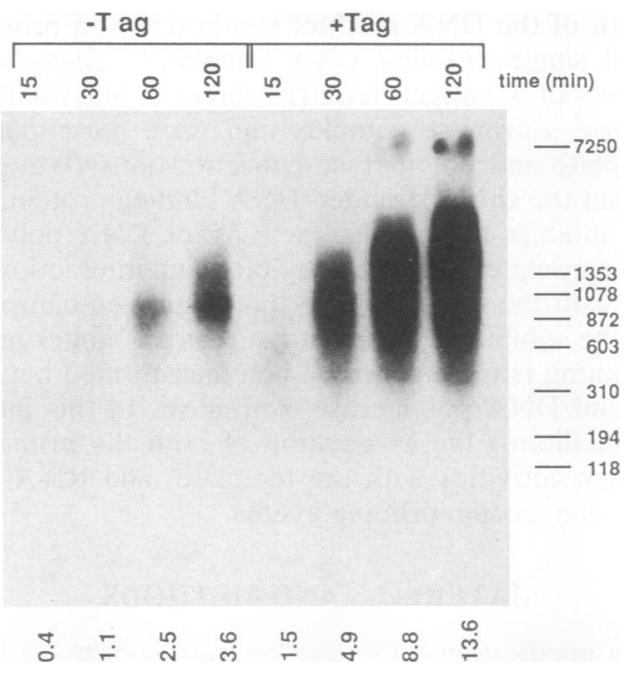

FIG. 3. Time course of DNA synthesis by DNA polymerase $\alpha$-primase on unprimed M13 single-stranded DNA in the presence or absence of $\mathrm{T}$ antigen (Tag). Reactions mixtures $(25 \mu \mathrm{l})$ containing $0.012 \mathrm{U}$ of polymerase activity, $0.002 \mathrm{U}$ of primase activity, $25 \mathrm{ng}$ of M13 single-stranded DNA, and 280 ng of T antigen (where indicated) were assembled on ice. Reaction products were isolated at the indicated times and electrophoresed on a $2 \%$ agarose alkaline gel. Picomoles of DNA synthesized in each reaction mixture are indicated at the bottom of the figure.

to that synthesized in the absence of $\mathrm{T}$ antigen was relatively constant over the whole time course, suggesting that the stimulatory effect of $T$ antigen was not simply a result of stabilizing DNA polymerase $\alpha$-primase against inactivation during incubation. This conclusion was confirmed by an experiment in which $T$ antigen was added to the reaction after $1 \mathrm{~h}$ of incubation. The amount of DNA synthesized during the subsequent hour of incubation $(3.7 \mathrm{pmol})$ was $75 \%$ of the DNA synthesized during the second hour of a parallel reaction that contained $T$ antigen for the entire $120 \mathrm{~min}$ of incubation $(4.9 \mathrm{pmol})$. This result indicated that there was little or no loss of DNA polymerase $\alpha$-primase activity during the first hour of incubation in the absence of $T$ antigen.

Figure 4 shows the effect of template concentration on the products synthesized by DNA polymerase $\alpha$-primase in the presence or absence of $T$ antigen. The amount of product synthesized increased with increasing template concentration up to about $2 \mathrm{mg} / \mathrm{ml}$ and then leveled off. At the higher DNA concentrations, the product synthesized in both the presence and absence of $T$ antigen was shorter than at low DNA concentrations, presumably because the higher template concentration favored starting new chains rather than extending preexisting chains. In addition, the stimulatory effect of $T$ antigen was reproducibly lower in magnitude at the highest template concentration.

RP-A suppresses DNA synthesis by DNA polymerase $\alpha$-primase on unprimed templates. In contrast to the effect of $T$ antigen, the addition of the mammalian single-stranded DNA binding protein, RP-A, strongly inhibited DNA synthesis on an unprimed DNA template (Fig. 5). This effect appeared to be due to a reduction in the number of new chains initiated rather than a decrease in the size of the products. The heterologous single-stranded DNA binding protein from Escherichia coli $(E$. coli SSB) also inhibited DNA synthesis (Fig. 5a). This result strongly suggests that RP-A inhibits 


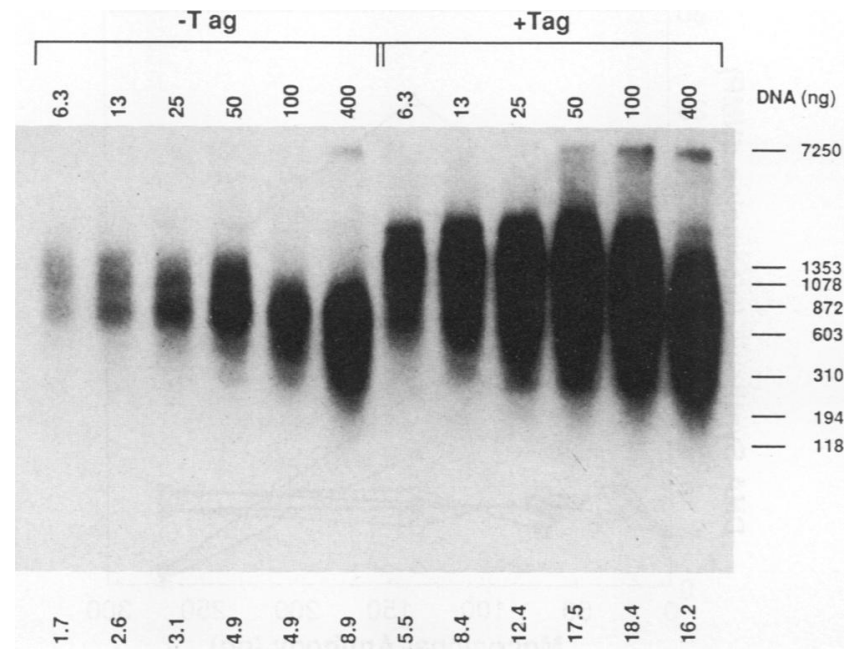

FIG. 4. Effect of DNA concentration on stimulation of DNA synthesis by $\mathrm{T}$ antigen (Tag). Reaction mixtures $(25 \mu \mathrm{l})$ containing $0.012 \mathrm{U}$ of DNA polymerase activity and $0.002 \mathrm{U}$ of primase activity were assembled on ice with the indicated amount of unprimed M13 single-stranded DNA plus or minus $280 \mathrm{ng}$ of T antigen. After incubation at $37^{\circ} \mathrm{C}$ for $2 \mathrm{~h}$, samples were electrophoresed on a $2 \%$ agarose alkaline gel and were visualized by autoradiography. Picomoles of DNA synthesized in each reaction mixture are indicated below the figure.

DNA polymerase $\alpha$-primase by blocking potential binding sites for DNA polymerase $\alpha$-primase on the template, rather than by interacting directly with the enzyme. The inhibition of DNA synthesis by either RP-A or $E$. coli SSB could be partially reversed by $\mathrm{T}$ antigen (Fig. $5 \mathrm{~b}$ ). In fact, the dependence of DNA polymerase activity on $\mathrm{T}$ antigen was reproducibly increased by the presence of either protein. For example, 60 ng of RP-A almost completely suppressed DNA synthesis by DNA polymerase $\alpha$-primase, but addition of T antigen to the reaction stimulated DNA synthesis more than eightfold (Fig. 5a).

Effects of $T$ antigen and RP-A on primer synthesis. To

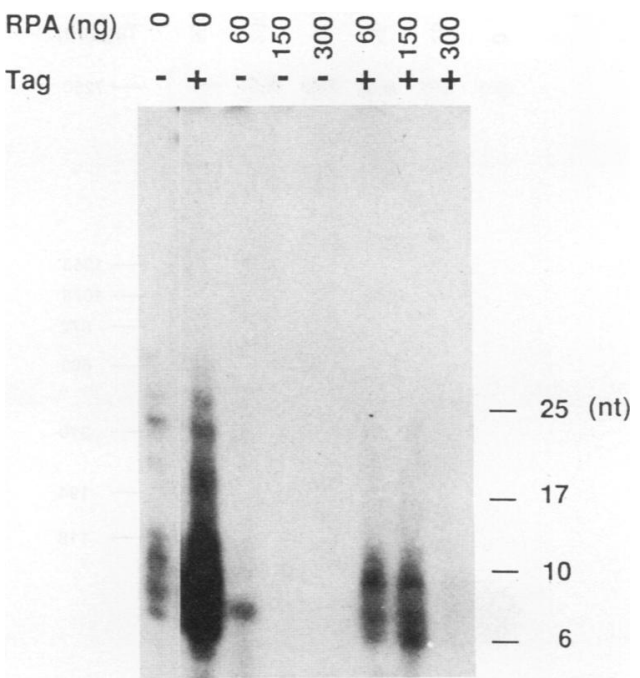

FIG. 6. Effects of T antigen (Tag) and RP-A on the DNA primase activity of DNA polymerase $\alpha$. Primase reaction mixtures $(25 \mu \mathrm{l})$ containing $0.0025 \mathrm{U}$ of primase, $0.0125 \mathrm{U}$ of polymerase, the indicated amount of RP-A, $20 \mu \mathrm{Ci}$ of $\left[\alpha{ }^{32} \mathrm{P}\right] \mathrm{CTP}(1 \mu \mathrm{M}), 50 \mu \mathrm{M}$ UTP, $50 \mu \mathrm{M}$ GTP, $4 \mathrm{mM}$ ATP, $25 \mathrm{ng}$ of unprimed M13 DNA, and $280 \mathrm{ng}$ of $\mathrm{T}$ antigen where indicated were assembled on ice. Reaction products were purified, electrophoresed on a denaturing $20 \%$ acrylamide gel, and visualized by autoradiography. nt, Nucleotides.

determine whether the DNA primase activity of DNA polymerase $\alpha$-primase complex was affected by $T$ antigen and RP-A, we measured the synthesis of primers directly in reaction mixtures lacking deoxyribonucleoside triphosphates. With DNA polymerase $\alpha$-primase alone, the products of the primase reaction consisted largely of ribonucleotide oligomers 6 to 12 nucleotides in length with a small amount of longer species (Fig. 6). $T$ antigen stimulated primer synthesis approximately fourfold, while RP-A strongly inhibited the reaction. Neither protein significantly affected the length distribution of primers. As for the DNA synthesis reactions described above, $T$ antigen partially
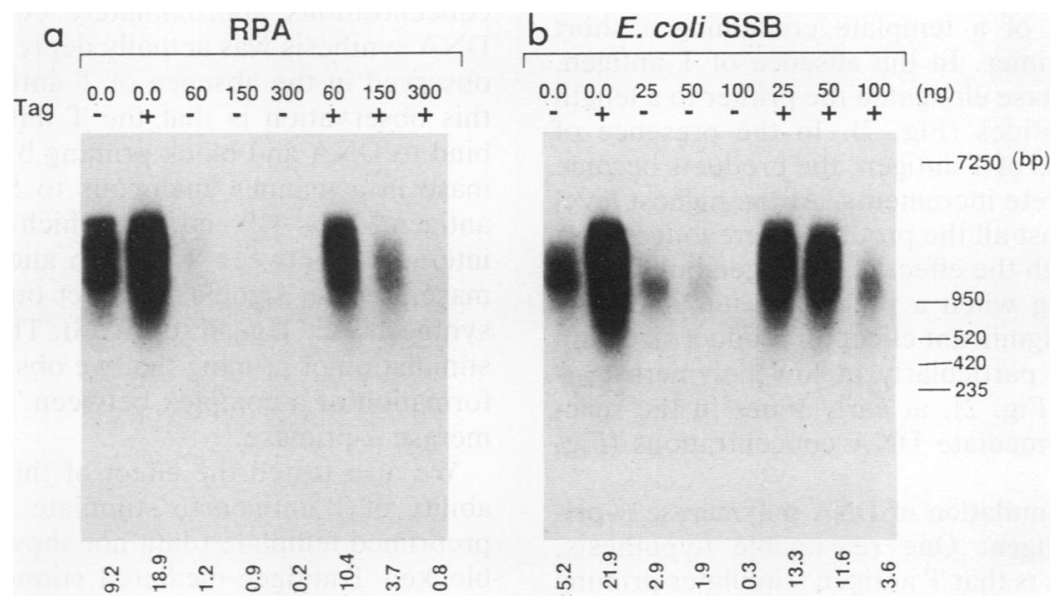

FIG. 5. Inhibition of DNA polymerase $\alpha$ by RP-A and E. coli SSB. Reaction mixtures $(25 \mu \mathrm{l})$ containing 0.0125 U of DNA polymerase activity, $0.0025 \mathrm{U}$ of primase activity, and $25 \mathrm{ng}$ of unprimed M13 single-stranded DNA were assembled on ice with the indicated amount of RP-A (39), E. coli SSB, or their respective buffers. Where indicated, the reaction mixtures contained $280 \mathrm{ng}$ of $\mathrm{T}$ antigen (Tag). Reaction mixtures were incubated for $2 \mathrm{~h}$ at $37^{\circ} \mathrm{C}$, and the products were electrophoresed on a $2 \%$ agarose alkaline gel. Picomoles of DNA synthesized in each reaction mixture are indicated at the bottom of the figure. 


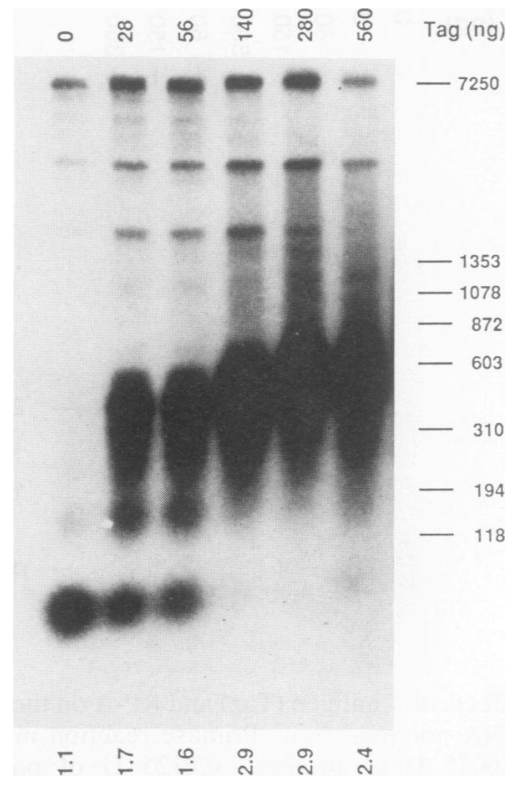

FIG. 7. Effect of $\mathrm{T}$ antigen (Tag) on primer extension. Reaction mixtures $(25 \mu \mathrm{l})$ lacking ribonucleoside triphosphates were assembled on ice with $0.012 \mathrm{U}$ of polymerase activity, $25 \mathrm{ng}$ of primed M13mp18 template, and the indicated amount of $\mathrm{T}$ antigen. After incubation for $2 \mathrm{~h}$ at $37^{\circ} \mathrm{C}$, the reaction products were electrophoresed on a $2 \%$ agarose alkaline gel and visualized by autoradiography. Picomoles of DNA synthesized in each reaction mixture are indicated at the bottom of the figure.

reversed the inhibition of primer synthesis by RP-A. Similarly, the stimulatory effects of $\mathrm{T}$ antigen on priming were greatest at low polymerase and template concentrations (data not shown). These findings indicate that $\mathrm{T}$ antigen and RP-A exert marked and antagonistic effects on the efficiency of primer synthesis by DNA polymerase $\alpha$-primase complex.

$T$ antigen increases the average size of the DNA products synthesized by DNA polymerase $\alpha$-primase complex. To determine whether $T$ antigen had an effect on the efficiency of primer elongation, we omitted ribonucleotides from the reaction and made use of a template containing a short oligodeoxynucleotide primer. In the absence of $\mathrm{T}$ antigen, DNA polymerase $\alpha$-primase elongated the primer to a length of less than 100 nucleotides (Fig. 7). In the presence of increasing concentrations of $\mathrm{T}$ antigen, the products became larger by relatively discrete increments. At the highest level of $\mathrm{T}$ antigen tested, almost all the products were longer than 300 nucleotides. Although the effect of $T$ antigen on product length was most striking when a preprimed template was used, we did observe a significant effect on product size with the unprimed template, particularly at low polymerase $\alpha$ primase concentration (Fig. 2), at early times in the reaction (Fig. 3), or at intermediate DNA concentrations (Fig. 4).

Effects of MAbs on stimulation of DNA polymerase $\alpha$-primase activity by $T$ antigen. One reasonable hypothesis, consistent with our data, is that $\mathrm{T}$ antigen stimulates priming and DNA synthesis via direct interaction with DNA polymerase $\alpha$-primase. Indeed, several groups have demonstrated that the two proteins can associate to form a specific complex $(8,9,28)$. The association of $T$ antigen and DNA polymerase $\alpha$-primase can be blocked by a specific subset of

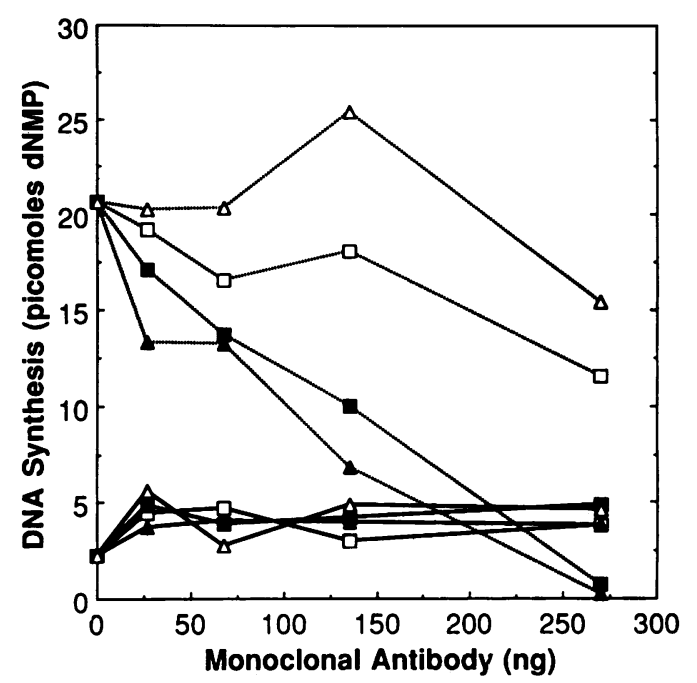

FIG. 8. Effects of MAbs on the stimulation of DNA polymerase $\alpha$ activity by $\mathrm{T}$ antigen (Tag) (unprimed template). Reaction mixtures $(25 \mu \mathrm{l})$ contained $0.0125 \mathrm{U}$ of polymerase activity, $0.0025 \mathrm{U}$ of primase activity, $25 \mathrm{ng}$ of M13 DNA, and the indicated amount of anti-T antigen MAb. Either no $\mathrm{T}$ antigen (-) or $350 \mathrm{ng}$ of $\mathrm{T}$ antigen $(. . .$.$) was added to each reaction mixture. The MAbs$ tested were MAb $419(\triangle)$, MAb $101(\square)$, MAb $205(\triangle)$, and MAb 414 (ם). MAb 419 (which binds an N-terminal epitope [1 to 82]) and MAb 101 (which binds a C-terminal epitope) do not inhibit SV40 DNA replication in vitro or formation of $\mathrm{T}$ antigen-DNA polymerase $\alpha$ complexes in crude extracts $(8,10,28,37)$. MAbs 205 and 414 bind the putative polymerase $\alpha$ interaction domain (363 to 708), inhibit SV40 DNA replication, and disrupt complex formation between $T$ antigen and polymerase $\alpha$ in crude cellular extracts $(8,10,28)$. The amount of DNA synthesized in $2 \mathrm{~h}$ at $37^{\circ} \mathrm{C}$ was quantitated by excising the lanes from the dried gel and counting their radioactivity in liquid scintillation cocktail.

MAbs directed against T antigen (e.g., MAb 205 and MAb 414) that do not affect other functions of $T$ antigen such as specific DNA binding $(10,28)$. These MAbs abolished the stimulation of purified DNA polymerase $\alpha$-primase by $T$ antigen on an unprimed template (Fig. 8). At antibody concentrations approximately equimolar with $\mathrm{T}$ antigen, DNA synthesis was actually depressed below the basal level observed in the absence of $\mathrm{T}$ antigen. One explanation for this observation is that the $\mathrm{T}$ antigen-antibody complexes bind to DNA and block priming by DNA polymerase $\alpha$-primase in a manner analogous to SSBs. In contrast, anti-T antigen MAbs 419 and 101, which do not block the physical interaction between T antigen and DNA polymerase $\alpha$-primase, had no significant effect on the stimulation of DNA synthesis (see legend to Fig. 8). These data indicate that the stimulation of priming that we observed very likely requires formation of a complex between $T$ antigen and DNA polymerase $\alpha$-primase.

We also tested the effect of this subset of MAbs on the ability of T antigen to stimulate DNA polymerase $\alpha$ on a preprimed template (data not shown). The same MAbs that blocked T-antigen-mediated stimulation of DNA synthesis on the unprimed template (205 and 414) blocked the T-antigen-mediated increase in product size on the preprimed template. None of the MAbs tested significantly affected polymerase activity or product size in the absence of $T$ antigen. 


\section{DISCUSSION}

While a number of studies have established that $\mathrm{T}$ antigen and DNA polymerase $\alpha$-primase can form a stable complex, the functional consequences of complex formation have not been addressed previously. The data presented here indicate that the interaction between the two proteins results in a dramatic increase in the ability of DNA polymerase $\alpha$-primase to initiate the synthesis of new DNA chains and to elongate such chains once initiated. Although our studies were done with model single-stranded templates, we believe that the conclusions are likely to be relevant to the replication of the duplex viral genome. The stimulatory effect of T antigen on DNA polymerase $\alpha$-primase activity occurs under experimental conditions identical to those used for the study of SV40 DNA replication in vitro. Moreover, the stimulation is greatest at low DNA polymerase and template concentrations and in the presence of the eukaryotic single-stranded DNA binding protein, RP-A, conditions which may closely resemble those operating during DNA replication.

The simplest explanation for the stimulatory effects that we observed is that $\mathrm{T}$ antigen acts to facilitate the interaction of DNA polymerase $\alpha$-primase with the template. It is known that T antigen binds to single-stranded DNA (29), and we have verified this fact by direct filter binding experiments performed under our replication conditions (data not shown). It follows that formation of a complex with DNA polymerase $\alpha$-primase would tether the enzyme to the DNA, increasing the frequency of productive encounters with potential template priming sites. By a similar argument, complex formation would be expected to increase the efficient utilization of primer termini by the DNA polymerase activity, resulting in the synthesis of longer DNA products. Thus, all the effects that we observed can be accounted for by a mechanism in which the primary role of $\mathrm{T}$ antigen is to increase the effective local concentration of DNA substrate in the neighborhood of DNA polymerase $\alpha$-primase. However, we cannot at this point rule out the possibility that $\mathrm{T}$ antigen has other, perhaps more direct, stimulatory effects on the activities of DNA polymerase $\alpha$-primase. For example, the helicase activity of $\mathrm{T}$ antigen may facilitate priming or polymerization in regions of stable secondary structure in the template. In addition, interaction with $\mathrm{T}$ antigen could result in structural alterations of DNA polymerase and/or primase that increase their intrinsic activities. Further work will be required to assess these possibilities.

Under the conditions of our experiments, DNA synthesis by DNA polymerase $\alpha$-primase is a multistep process. The initial step is the synthesis of a ribonucleotide primer by the primase activity of the enzyme. The primase then dissociates from the primer terminus, allowing the DNA polymerase subunit to bind. After synthesis of a short DNA chain, the DNA polymerase dissociates, but the released primer terminus can serve as a substrate for additional elongation events. Most of the final DNA products that we observed were generated as a result of multiple binding and dissociation events by DNA polymerase $\alpha$-primase. This is evident from the fact that the products decrease in length as the template concentration is increased (Fig. 4). The multistep nature of the overall process of DNA synthesis may also account for the sigmoidal relationship between total synthesis and DNA polymerase concentration observed in the absence of $T$ antigen (Fig. 2b). We suggest that this relationship becomes more linear in the presence of $\mathrm{T}$ antigen because tethering of DNA polymerase $\alpha$-primase to the template allows a number
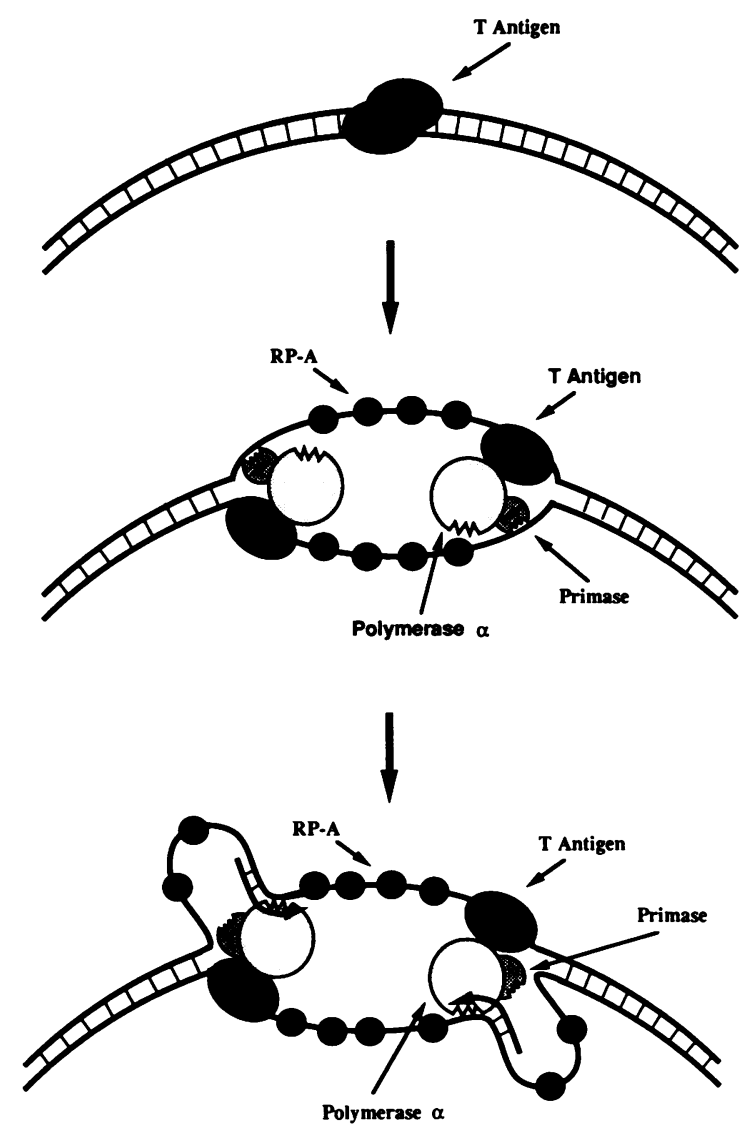

FIG. 9. Model of the initiation reaction. See text for details.

of binding-synthesis-dissociation events to occur before the enzyme diffuses away into the bulk solution.

It seems likely that the interaction between $T$ antigen and DNA polymerase $\alpha$-primase is important for determining the specificity of initiation events during SV40 DNA replication. In the initial phase of the replication reaction, $T$ antigen binds specifically to the viral origin and then functions as a helicase to unwind the two strands of the duplex $(6,40)$. Model studies indicate that a $\mathrm{T}$ antigen helicase translocates in the $3^{\prime}-$ to- $^{\prime}$ ' direction along each parental strand, thus generating two potential replication forks $(30,37,38)$. As illustrated in Fig. 9, we suggest that DNA polymerase $\alpha$-primase forms a specific complex with $T$ antigen at each fork and that the geometry of this complex facilitates primer synthesis on the lagging strand. This model, in which the T antigen-DNA polymerase $\alpha$-primase complex functions as a mobile priming apparatus, is analogous to many prokaryotic systems in which primase activity and helicase activity reside in either a single polypeptide chain (bacteriophage $\mathrm{T} 7$ ) (reviewed in reference 26) or a complex of polypeptide chains (phage T4 and $E$. coli) $(1,15,17)$. The polarity of translocation of $\mathrm{T}$ antigen is the opposite of the prokaryotic primosome $\left(5^{\prime}\right.$ to $\left.3^{\prime}\right)$. However, helicases that translocate in both directions have been identified within the $E$. coli primosome $(16,18)$. In our model, $T$ antigen moves on the leading strand but positions DNA polymerase $\alpha$-primase so that primer synthesis takes place preferentially on the opposite (lagging) strand.

Previous studies have demonstrated that the singlestranded DNA binding protein, RP-A, has a small stimula- 
tory effect on the ability of DNA polymerase $\alpha$ to elongate a pre-formed primer $(14,19,33)$. This observation, which we confirmed, indicates that RP-A does not block the interaction of DNA polymerase $\alpha$ with a primer terminus. Our finding that RP-A inhibited priming by DNA polymerase $\alpha$-primase indicates that RP-A prevents the productive interaction of DNA primase with unprimed single-stranded DNA and defines an additional function for the protein in suppressing nonspecific priming events. We suggest that most of the single-stranded DNA in replication intermediates will be complexed with RP-A and inaccessible to the primase activity of DNA polymerase $\alpha$-primase. Thus, in a manner similar to gene 32 of bacteriophage T4 $(4,27)$, and the SSB of $E$. coli (2), RP-A may prevent nonproductive priming events by suppressing primase activity everywhere except at the replication fork (Fig. 9).

It seems clear that the functional interaction of $\mathrm{T}$ antigen with DNA polymerase $\alpha$-primase plays an important role in the initiation of DNA synthesis during SV40 DNA replication. It is plausible to speculate that similar interactions, involving cellular counterparts of $\mathrm{T}$ antigen, occur during initiation of cellular DNA synthesis. Moreover, modulation of such interactions by either phosphorylation or protein interactions could provide a mechanism for regulating DNA replication. In this regard, it is intriguing that the antioncogene p53, which is inhibitory to SV40 DNA replication (3, 34 ), competes with polymerase $\alpha$-primase for binding to $T$ antigen in crude cellular extracts $(9,10)$.

\section{ACKNOWLEDGMENTS}

We thank Marc Wold for providing RP-A, David Weinberg for assistance with protein purification, and the laboratory of Roger McMacken (The Johns Hopkins University School of Hygiene) for the generous gift of $E$. coli SSB. We thank Pamela Simancek and Alicia Russo for expert technical assistance. We are grateful to members of our laboratory and the laboratory of Philip Hieter for useful discussions and critical reading of the manuscript.

K.L.C. is the recipient of a Medical Scientist Training Program award and research was supported by grant 2RO1CA4014-06 from the National Cancer Institute.

\section{REFERENCES}

1. Alberts, B. M. 1987. Prokaryotic DNA replication mechanisms. Philos. Trans. R. Soc. London 317:395-420.

2. Arai, K., and A. Kornberg. 1979. A general priming system employing only dnaB protein and primase for DNA replication. Proc. Natl. Acad. Sci. USA 76:4308-4312.

3. Braithwaite, A. W., H. Sturzbecher, C. Addison, C. Palmer, K. Rudge, and J. R. Jenkins. 1987. Mouse p53 inhibits SV40 origin-dependent DNA replication. Nature (London) 329:458460.

4. Cha, T., and B. M. Alberts. 1990. Effects of the bacteriophage T4 gene 41 and gene 32 proteins on RNA primer synthesis: coupling of leading- and lagging-strand DNA synthesis at a replication fork. Biochemistry 29:1791-1798.

5. Challberg, M. D., and T. J. Kelly. 1989. Animal virus DNA replication. Annu. Rev. Biochem. 58:671-717.

6. Dean, F. B., P. Bullock, Y. Murakami, C. R. Wobbe, L. Weissbach, and J. Hurwitz. 1987. Simian virus 40 (SV40) DNA replication: SV40 large T antigen unwinds DNA containing the SV40 origin of replication. Proc. Natl. Acad. Sci. USA 84:1620.

7. Dodson, M., F. B. Dean, P. Bullock, H. Echols, and J. Hurwitz. 1987. Unwinding of duplex DNA from the SV40 origin of replication by $\mathrm{T}$ antigen. Science 238:964-967.

8. Dornreiter, I., A. Hoss, A. K. Arthur, and E. Fanning. 1990. SV40 $\mathrm{T}$ antigen binds directly to the large subunit of purified DNA polymerase alpha. EMBO J. 9:3329-3336.

9. Gannon, J. V., and D. P. Lane. 1987. p53 and DNA polymerase alpha compete for binding to SV40 T antigen. Nature (London) 329:456-458.

10. Gannon, J. V., and D. P. Lane. 1990. Interactions between SV40 $T$ antigen and DNA polymerase $\alpha$. New Biol. 2:84-92.

11. Hurwitz, J., F. B. Dean, A. D. Kwong, and S. Lee. 1990. The in vitro replication of DNA containing the SV40 origin. J. Biol. Chem. 265:18043-18046.

12. Ishimi, Y., A. Claude, P. Bullock, and J. Hurwitz. 1988. Complete enzymatic synthesis of DNA containing the SV40 origin of replication. J. Biol. Chem. 263:19723-19733.

13. Kelly, T. J. 1988. SV40 DNA replication. J. Biol. Chem. 263:17889-17892.

14. Kenny, M. K., S.-H. Lee, and J. Hurwitz. 1989. Multiple functions of human single-stranded DNA binding protein in simian virus 40 DNA replication: single strand stabilization and stimulation of DNA polymerases alpha and delta. Proc. Natl. Acad. Sci. USA 86:9757-9761.

15. Kornberg, A. 1980. DNA Replication. W. H. Freeman Publications, San Francisco.

16. Lasken, R. S., and A. Kornberg. 1988. The primosomal protein $\mathrm{n}^{\prime}$ of Escherichia coli is a DNA helicase. J. Biol. Chem. 263:5512-5518.

17. LeBowitz, J. H., and R. McMacken. 1986. The Escherichia coli dnaB replication protein is a DNA helicase. J. Biol. Chem. 261:4738-4748.

18. Lee, M. S., and K. J. Marians. 1987. Escherichia coli replication factor $\mathrm{Y}$, a component of the primosome, can act as a DNA helicase. Proc. Natl. Acad. Sci. USA 84:8345-8349.

19. Lee, S.-H., T. Eki, and J. Hurwitz. 1989. Synthesis of DNA containing the simian virus 40 origin of replication by the combined action of DNA polymerases alpha and delta. Proc. Natl. Acad. Sci. USA 86:7361-7365.

20. Lehman, I. R., and L. S. Kaguni. 1989. DNA polymerase $\alpha$. J. Biol. Chem. 264:4265-4268.

21. Li, J. J., and T. J. Kelly. 1984. Simian virus 40 DNA replication in vitro. Proc. Natl. Acad. Sci. USA 81:6973-6977.

22. Li, J. J., and T. J. Kelly. 1985. Simian virus 40 DNA replication in vitro: specificity of initiation and evidence for bidirectional replication. Mol. Cell. Biol. 5:1238-1246.

23. Maniatis, T., E. F. Fritsch, and J. Sambrook. 1982. Molecular cloning: a laboratory manual. Cold Spring Harbor Laboratory, Cold Spring Harbor, N.Y.

24. Murakami, Y., C. R. Wobbe, L. Weissbach, F. B. Dean, and J. Hurwitz. 1986. Role of DNA polymerase $\alpha$ and DNA primase in simian virus 40 DNA replication in vitro. Proc. Natl. Acad. Sci. USA 83:2869-2873.

25. Prelich, G., and B. Stillman. 1988. Coordinated leading and lagging strand synthesis during SV40 DNA replication in vitro requires PCNA. Cell 53:117-126.

26. Richardson, C. C. 1983 . Bacteriophage T7: minimal requirements for the replication of a duplex DNA molecule. Cell 33:315-317.

27. Richardson, R. W., and N. G. Nossal. 1989. Trypsin cleavage in the $\mathrm{COOH}$ terminus of the bacteriophage T4 gene 41 DNA helicase alters the primase-helicase activities of the T4 replication complex in vitro. J. Biol. Chem. 264:4732-4739.

28. Smale, S. T., and R. Tjian. 1986. T-antigen-DNA polymerase alpha complex implicated in simian virus 40 DNA replication. Mol. Cell. Biol. 6:4077-4087.

29. Spillman, T., D. Giacherio, and L. P. Hager. 1979. Single strand DNA binding of simian virus 40 tumor antigen. J. Biol. Chem. 254:3100-3104.

30. Stahl, H., P. Droge, and R. Knippers. 1986. DNA helicase activity of SV40 large tumor antigen. EMBO J. 5:1939-1944.

31. Stillman, B. 1989. Initiation of eukaryotic DNA replication in vitro. Annu. Rev. Cell Biol. 5:197-245.

32. Tsurimoto, T., T. Melendy, and B. Stillman. 1990. Sequential initiation of lagging and leading strand synthesis by two different polymerase complexes at the SV40 DNA replication origin. Nature (London) 346:534-539.

33. Tsurimoto, T., and B. Stillman. 1989. Multiple replication factors augment DNA synthesis by the two eukaryotic DNA polymerases, alpha and delta. EMBO J. 8:3883-3889. 
34. Wang, E. H., P. N. Friedman, and C. Prives. 1989. The murine p53 protein blocks replication of SV40 DNA in vitro by inhibiting the initiation functions of SV40 large T antigen. Cell 57:379-392.

35. Weinberg, D. H., K. L. Collins, P. Simancek, A. Russo, M. S. Wold, D. M. Virshup, and T. J. Kelly. 1990. Reconstitution of SV40 DNA replication with purified proteins. Proc. Natl. Acad. Sci. USA 87:8692-8696.

36. Weinberg, D. H., and T. J. Kelly. 1989. Requirement for two DNA polymerases in the replication of simian virus 40 DNA in vitro. Proc. Natl. Acad. Sci. USA 86:9742-9746.

37. Wiekowski, M., P. Droge, and H. Stahl. 1987. Monoclonal antibodies as probes for a function of large $\mathrm{T}$ antigen during the elongation process of simian virus 40 DNA replication. J. Virol. 61:411-418.
38. Wobbe, C. R., L. Weissbach, J. A. Borowiec, F. B. Dean, Y. Murakami, P. Bullock, and J. Hurwitz. 1987. Replication of SV40-origin-containing DNA with purified proteins. Proc. Natl. Acad. Sci. USA 84:1834-1838.

39. Wold, M. S., and T. J. Kelly. 1988. Purification and characterization of replication protein A, a cellular protein required for in vitro replication of simian virus 40 DNA. Proc. Natl. Acad. Sci. USA 85:2523-2527.

40. Wold, M. S., J. J. Li, and T. J. Kelly. 1987. Initiation of simian virus 40 DNA replication in vitro: large-tumor-antigen- and origin-dependent unwinding of the template. Proc. Natl. Acad. Sci. USA 84:3643-3647.

41. Wold, M. S., D. W. Weinberg, D. M. Virshup, J. J. Li, and T. J. Kelly. 1989. Identification of cellular proteins required for SV40 DNA replication. J. Biol. Chem. 264:2801-2809. 